\title{
THE NEWER GENERATION INTRAOCULAR LENS POWER CALCULATION FORMULAE IN ANTERIOR CHAMBER IMPLANTS
}

\author{
PALANISWAMY SUNDERRAJ and JOSE R. VILLADA \\ Southport
}

\begin{abstract}
SUMMARY
One hundred and fifty-one eyes with anterior chamber implants and a best corrected visual acuity of at least 6/12 were studied to compare the predictive accuracies of the newer generation intraocular lens power calculation formulae. There was no statistically significant difference between the predictive accuracies of the SRK (SandersRetzlaff-Kraff), SRK II, SRK/Theoretical (SRK/T) and Holladay formulae. All these four formulae were more accurate than the Binkhorst II formula.
\end{abstract}

Several formulae are available for calculating intraocular lens (IOL) power. Theoretical formulae ${ }^{1-3}$ were used initially followed by the development of more accurate empirical formulae. The commonly used Sanders-Retzlaff-Kraff or SRK regression formula ${ }^{3}$ has been modified $(\text { SRK II })^{4}$ to take into account the non-linear relationship between axial length and IOL power. Other widely used IOL power calculation formulae include the Binkhorst II theoretical formula ${ }^{5}$ and the newly described Holladay ${ }^{6,7}$ and SRK/Theoretical $(\mathrm{SRK} / \mathrm{T})^{8}$ formulae. Although the newer generation IOL power calculation formulae have been extensively evaluated in posterior chamber IOLs, ${ }^{4-11}$ the same is not true of anterior chamber implants. ${ }^{7}$ Hence we evaluated the predictive accuracies of the three SRK formulae in eyes which had undergone anterior chamber IOL implantation and compared them with the Binkhurst II and Holladay formulae.

\section{MATERIALS AND METHODS}

All cases of anterior chamber IOL implantation performed at our hospital, either as a secondary procedure for aphakia or following rupture of the posterior capsule in intended extracapsular extraction, between January 1984 and May 1991 were reviewed. We excluded cases of combined tra-

From: Department of Ophthalmology, District General Hospital, Southport PR8 6NJ, UK.

Correspondence to: Mr. P. SunderRaj, FCOphth, FRCS, Medical Adviser, Ciba Vision Ophthalmics, Flanders Road, Hedge End, Southampton SO3 3LG, UK. beculectomy and anterior chamber IOL implantation, and also any cases in which best corrected postoperative visual acuity was $<6 / 12$ or for which postoperative refraction data were incomplete. The 151 eyes with anterior chamber IOLs which met the inclusion criteria were studied to evaluate the predictive accuracies of the various IOL power calculation formulae.

All the implantations were performed by five surgeons using essentially identical surgical techniques. The anterior chamber lenses implanted were of the same style and made by a single manufacturer (Kelman Multiflex MT Series, Cilco).

IOL power was calculated from measurements of axial length and corneal curvature. Axial length was measured by applanation (A scan ultrasonography) using the Cilco Sonometrics Digicon or Coopervision Ultrascan Digital B 2000. Corneal curvature was measured with a Topcon OM-4 keratometer. The software program within the ultrasound equipment was used to calculate the emmetropic IOL power and the predicted postoperative refraction for multiple IOL powers based on the SRK or SRK II formulae with the manufacturer-recommended ' $\mathrm{A}$ ' constant of 115.3. The actual power of the IOL implanted by the surgeon in each case depended on the refractive needs of the patient and the state of the lens and the refraction in the fellow eye. Postoperative refractions used in this study were carried out between 8 and 12 weeks postoperatively or when spectacles were prescribed.

The Binkhorst II formula and the three SRK formulae, with the respective manufacturer-recommended constant ('A' constant or anterior chamber depth), were used to predict the postoperative refraction in each patient for the lens power implanted by the surgeon. In the case of the Holladay formula, an S-factor was calculated from the 'A' constant and applied. The value (in dioptres) of the difference between the predicted postoperative refraction and the actual postoperative refraction (spherical equivalence in dioptres), termed the predictive error, was computed in each individual case for the five formulae under evaluation. 
Table I. Mean (SD) predictive error of the formulac evaluated (in dioptres)

\begin{tabular}{|c|c|c|c|c|c|}
\hline \multirow[b]{2}{*}{ Axial length (mm) } & \multicolumn{5}{|c|}{ Formulae evaluated } \\
\hline & SRK & SRK II & $\mathrm{SRK} / \mathrm{T}$ & Holladay & Binkhorst II \\
\hline$<22$ & $1 . .31(1.25)$ & $1.48(1.01)$ & 1.49 (1.0.3) & $1.35(1.07)$ & $1.39(1.11)$ \\
\hline $22-24.49$ & $1.19(1.0 .3)$ & $1.20(1.03)$ & $1.21(0.98)$ & $1.23(1.07)$ & $1.49(1.16)$ \\
\hline$\geqslant 24.5$ & $0.85(0.63)$ & $1.14(0.96)$ & $1.09(0.97)$ & $1.07(0.87)$ & $1.57(0.98)$ \\
\hline All eyes & $1.12(0.96)$ & $1.24(1.01)$ & $1.22(1.01)$ & $1.21(0.97)$ & $1.49(1.07)$ \\
\hline
\end{tabular}

The predictive accuracies of the five formulae evaluated were compared on the basis of mean 'absolute' predictive error and its standard deviation, and the distribution of the predictive errors (percentage of cases with actual postoperative refraction within 1 or 2 dioptres respectively of predicted postoperative refraction). The statistical significance of the difference between the various IOL power calculation formulae evaluated was assessed using (1) Student's paired $t$ test on the mean absolute predictive error of the different formulae and (2) the chi-squared test on the number of patients within 1 dioptre of predictive error for the various formulae under evaluation.

\section{RESULTS}

Table I shows the mean absolute predictive errors of each of the formulae evaluated for anterior chamber IOL implantation in eyes of different axial lengths. These eyes were classified according to the approach of Sanders et $\mathrm{al}^{+}{ }^{+}$ as short eyes $(<22 \mathrm{~mm})$, long eyes $(\geqslant 24.5 \mathrm{~mm})$ or average eyes. There were 33 short eyes, 43 long eyes and 75 eyes of average axial length. The SRK formula had the smallest mean predictive error overall. This was statistically significant when compared with the Binkhorst II formula $(p<0.003)$ but not with the other formulae evaluated. Also, the SRK II $(p<0.04)$, SRK/T $(p<0.03)$ and Holladay $(p<0.02)$ formulae were significantly more accurate than the Binkhorst II formula when all the eyes were considered. The SRK formula had the smallest mean predictive error within the different subsets of eyes studied. However, this was statistically significant only when compared with the Binkhorst II formula in long eyes $(p<0.0() 1)$. The SRK II $(p<0.05)$. SRK/T $(p<0.02)$ and Holladay $(p<0 .() 1)$ formulae were more accurate than the Binkhorst II formula in long eyes.

The distribution of the predictive errors of the formulae evaluated in eyes of different axial length groups is shown in Table II. The predictive errors are shown as cumulative percentages within 1 dioptre and within 2 dioptres for each of the various IOL power calculation formulae evaluated. The predictive accuracies of the Holladay and SRK formulae were similar. Both the SRK $(p<0.025)$ and Holladay $(p<0.05)$ formulae were more accurate than the Binkhorst II formula.

\section{DISCUSSION}

In this study of various IOL power calculation formulae in anterior chamber IOL implantation. the SRK. SRK II, SRK/T and Holladay formulae were more accurate than the Binkhorst II formula. However, in contrast to our observations, in a previous report ${ }^{7}$ the predictive accuracy of the Binkhorst II formula in anterior chamber IOLs was better than that of the SRK and SRK II empirical formulae. This difference between studies may be attributed to the several surgeon-specific variables which affect the accuracy of the IOL power calculation formulae. These variables include the method of ocular biometry, the surgical technique, the type and style of IOL implanted, and the IOL manufacturer. ${ }^{0.12 .13}$ Consequently, it is ideal for each ophthalmic surgeon to use the most accurate formula for his or her own practice by comparing the performance

Table II. Distribution of predictive error of the formulate evaluated (in cumulative percentages)

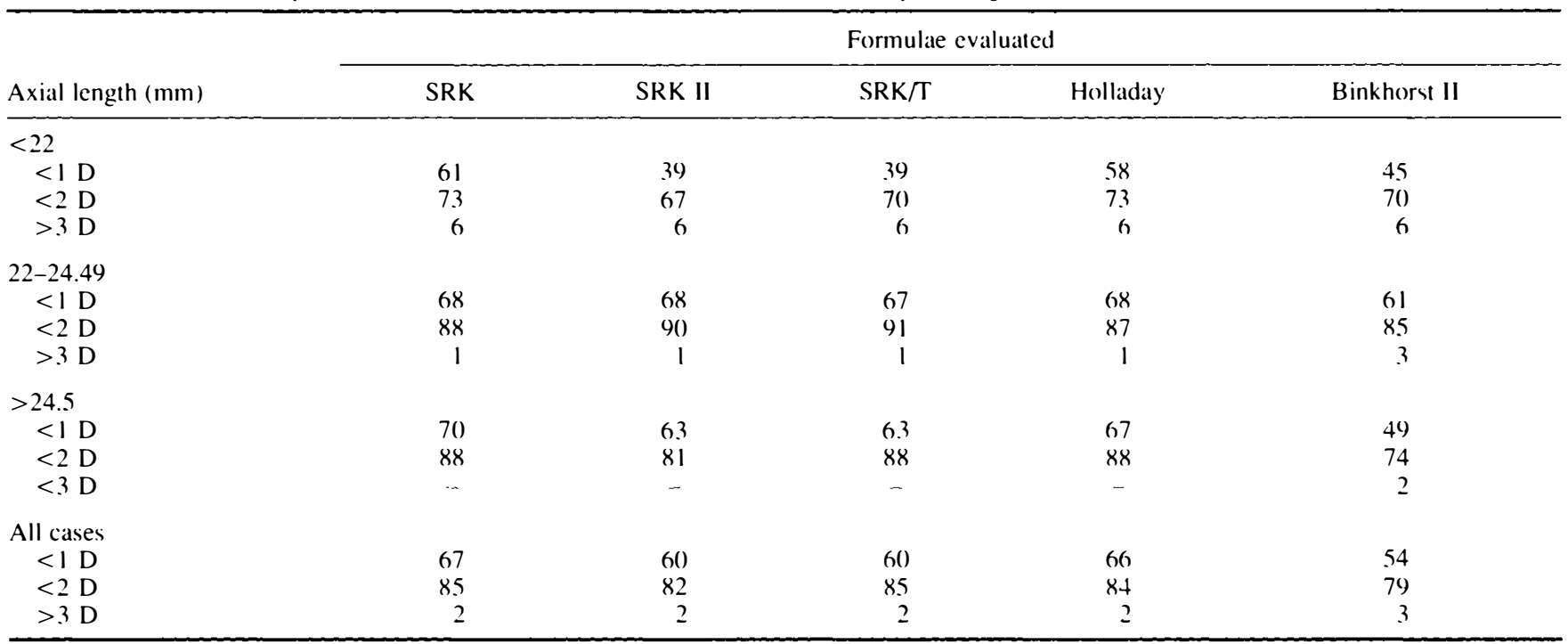


of the various formulae in a sample of patients after maintaining constant the factors that affect IOL power calculation.

The newly described SRK II formula is different from the original SRK formula in two ways: (1) the 'A' constant is not fixed but dependent on the axial length of a given eye and (2) it uses a variable refraction factor of 1.25 for emmetropic IOL $\leqslant 14$ dioptres and 1.0 for emmetropic IOL $<14$ dioptres while the SRK formulae use a constant refraction factor of 1.5. The inverse of the refraction factor indicates the amount of change in postoperative refraction that will result for each dioptre of IOL power, above or below the IOL power required for emmetropia. In posterior chamber IOLs the SRK II formula was more accurate than the original SRK formula from which it was derived. ${ }^{46}$ In this study of anterior chamber IOLs the SRK II formula had a similar accuracy to the SRK formula, and in a previous report ${ }^{7}$ it was less accurate than the SRK formula in long eyes. This may be because the SRK II formula was based on data which included only posterior chamber IOLs. Hence the SRK II formula may be more accurate than the SRK formula in posterior chamber IOLs $s^{4.6}$ but not in anterior chamber IOLs.

The accuracy of the SRK/T formula in the calculation of power of posterior chamber IOLs was similar to that of the SRK II formula except in eyes of axial length $>28.4 \mathrm{~mm}^{8}$ In this study of anterior chamber implants, the accuracy of the SRK/T formula was greater than that of the Binkhorst II formula but similar to that of the SRK, SRK II and Holladay formulae.

The use of optimised constants has been shown to improve the accuracy of various IOL power calculation formulae in posterior chamber intraocular lenses. ${ }^{4.6 .9 .11 .14}$ This result has not yet been unequivocally demonstrated in anterior chamber IOLs. ${ }^{15}$ We used the manufacturerrecommended constants in this study since the aim was to evaluate the comparative performance of the various IOL power calculation formulae in anterior chamber IOLs without any user modifications.

We thank A. E. Lewis for administrative help, M. Lynch for help with the computerised data analysis, K. Devi SunderRaj for secretarial assistance, $\mathrm{Mr} \mathrm{A}$. P. Watson and $\mathrm{Mr} \mathrm{A}$. O. Akingbehin for allowing us to study their patients, and K. Priestley of Hum- phrey Instruments for providing the SRK/Theoretical formula computer software.

Key words: Anterior chamber lens, Biometry, Empirical formula, Intraocular lens power calculation, Theoretical formula.

\section{REFERENCES}

1. Colenbrander MC: Calculation of the power of an iris clip lens for distant vision. Br J Ophthalmol 1973, 57: 735-40.

2. Binkhorst CD: Dioptrienzahl kunstlicher Augenlinsen. Klin Monatsbl Augenheilkd 1973, 162: 354-61.

3. Sanders D, Retzlaff J, Kraff M, Kratz R: Comparison of the accuracy of the Binkhorst. Colenbrander and SRK implant power prediction formulas. Am Intraocul Implant Soc $J$ 1981, 7: 337-40.

4. Sanders DR, Retzlaff J, Kraff MC: Comparison of the SRK II formula and other second generation formulas.J Cataract Refract Surg 1988, 14: 136-41.

5. Holladay JT, Praeger TC. Chandler TY, Musgrove KH: A three-part system for refining intra-ocular lens power calculations. J Cataract Refiact Surg 1988, 14: 17-24.

6. Dang MS. SunderRaj P: SRK II formula in the calculation of intra-ocular lens power. Br.J Ophthalmol 1989, 73: 82.3-6.

7. Richards SC, Steen DW: Clinical evaluation of the Holladay and SRK II formulas. J Cataract Refiact Surg 1990, 16: $71-4$.

8. Sanders DR, Retzlaff JA. Kraff MC, Gimbel HV, Raanan MG: Comparison of the SRK/T formula and other theoretical and regression formulas. I Cataract Refiact Surg 1990. 16: 341-6.

9. Olsen T, Thim K, Corydon L: Theoretical versus SRK I and SRK II calculation of intraocular lens power. J Cataract Refract Surg 1990, 16: 217-25.

10. Coburn RM, Grandon SC, Grandon SC: Intraocular lens implant power calculations: investigations controlling for lens type. J Cataract Refiact Surg 1990, 16: 547-64.

11. Olsen T, Thim K, Corydon L: Accuracy of the newer generation intraocular lens power calculation formulas in long and short eyes. J Cataract Refract Surg 1991. 17: 187-93.

12. Richards SC, Olson RJ, Richards WL, Brodstein RS, Hale PN: Clinical evaluation of six intra-ocular calculation formulas. Am Intraocul Implant Soc .J 1985, 11: 153-8.

13. Halliday BL: Calculation of intra-ocular lens power-results in practice. Trans Ophthalmol Soc UK 1986, 105: 435-40.

14. Dang MS, SunderRaj P: Calculation of the power of posterior chamber implants. Afi Asian J Ophthalmol 1990, 8: 142-5.

15. Villada JR. SunderRaj P, Akingbehin T: Calculation of the power of anterior chamber implants. Br. I Ophthalmol 1992. 76: $303-6$. 